\title{
Improved cytodiagnostics and quality of patient care through double reading of selected cases by an expert cytopathologist
}

\author{
Chantal C. H. J. Kuijpers • Mike Visser • Daisy M. D. S. Sie-Go • \\ Henk de Leeuw • Mathilda J. de Rooij • Paul J. van Diest • \\ Mehdi Jiwa
}

Received: 3 December 2014 / Revised: 2 February 2015 / Accepted: 4 February 2015 /Published online: 17 March 2015

(C) The Author(s) 2015. This article is published with open access at Springerlink.com

\begin{abstract}
Double reading may be a valuable tool for improving the quality of patient care by restoring diagnostic errors before final sign-out, but standard double reading would significantly increase costs of pathology. The aim of this study was to assess the added value of routine double reading of defined categories of clinical cytology specimens by specialized cytopathologists. Specialized cytopathologists routinely re-diagnosed blinded defined categories of clinical cytology specimens that had been signed out by routine pathologists from January 2012 up to December 2013. Major and minor discordance rates between initial and expert diagnoses were determined, and both diagnoses were validated by comparison with same-site histological follow-up. Initial and expert diagnoses were concordant in 131/218 specimens (60.1\%). Major and minor discordances were present in $28(12.8 \%)$ and 59 (27.1\%) specimens, respectively. Pleural fluid, thyroid and urine specimens showed the highest major discordance rates (19.4, 19.2 and $16.7 \%$, respectively). Histological follow-up (where possible) supported the expert diagnosis in $95.5 \%$ of specimens. Our implemented double reading strategy of defined categories of cytology specimens showed major discordance in $12.8 \%$ of specimens. The expert diagnosis was sup-
\end{abstract}

C. C. H. J. Kuijpers $•$ M. Visser • D. M. D. S. Sie-Go $\cdot$ H. de Leeuw $•$ M. J. de Rooij

Symbiant Pathology Expert Centre, Alkmaar, The Netherlands

C. C. H. J. Kuijpers · D. M. D. S. Sie-Go · P. J. van Diest • M. Jiwa Department of Pathology, University Medical Centre Utrecht, Utrecht, The Netherlands

C. C. H. J. Kuijpers

PALGA, Houten, The Netherlands

\section{Jiwa $(\triangle)$}

Department of Pathology, Alkmaar Medical Centre, Symbiant

Pathology Expert Centre, PO Box 501, 1815

JD Alkmaar, The Netherlands

e-mail: m.jiwa@mca.nl ported in $95.5 \%$ of discordant cases where histological follow-up was available. This indicates that this double reading strategy is worthwhile and contributes to better cytodiagnostics and quality of patient care, especially for suspicious pleural fluid, thyroid and urine specimens. Our results emphasize that cytopathology is a subspecialization of pathology and requires specialized cytopathologists.

Keywords Cytopathology · Diagnostic accuracy · Patient safety $\cdot$ Quality assurance $\cdot$ Subspecialization

\section{Introduction}

There is a growing awareness that pathology diagnosis is not infallible and that diagnostic errors may lead to under- or overtreatment and thereby compromise patient safety. Double reading is a potentially valuable tool for reducing diagnostic errors and thereby improving the quality of patient care. It may reveal inaccurate diagnoses that otherwise might have led to improper or unnecessary patient management or treatment. In response to the Institute of Medicine report 'To err is human; building a safer health system' from 1999 [1], the American Society for Clinical Pathology (ASCP) recognized second opinion as a key aspect in the assurance of patient safety for histological and cytological diagnoses [2]. They recommended to consider second opinion in several situations, including highly critical or significant cases, problemprone cases and cases suggested for review by clinicians [2].

Many studies focused on second opinion in diagnostic surgical pathology and reported major diagnostic disagreement rates of 2 to $28 \%$, mainly depending on the organ system studied [3-24]. A smaller number of studies focused on second opinion in cytopathology, of which the majority reported 
disagreement rates of specific organs or organ systems, predominantly the thyroid [25-31]. Few studies, however, assessed the impact of double reading on patient care for the whole subset of cytological specimens. These studies reported major disagreement rates ranging from 7.4 to $9.3 \%$ [32-34], and second opinion diagnoses were better supported by histological follow-up than the initial diagnoses [32, 33].

Therefore, we implemented intradepartmental double reading by expert cytopathologists on January 1, 2012. Since routine double reading of all specimens would significantly increase costs, we predefined selected categories of cytology cases where the yield of double reading was expected to be highest. In this study, we assessed the added value of this expert double reading strategy. To this end, we retrospectively determined the rates of concordance and major and minor discordance between initial and second opinion diagnoses of all cytology cases reviewed by the expert cytopathologists. Furthermore, we validated both diagnoses by comparison with same-site histological follow-up.

\section{Materials and methods}

\section{Routine intradepartmental second review}

Figure 1 demonstrates the routine cytology diagnostics process at Symbiant's three pathology laboratories (Alkmaar Medical Centre, Westfriesgasthuis Hoorn and Zaandam Medical Centre). All cytological specimens were routinely prescreened for abnormalities by one or two cytotechnicians. Subsequently, the prescreened specimens are examined by either a general pathologist (in the Alkmaar and Hoorn laboratories) or both general pathologists and expert cytopathologists in the Zaandam laboratory.

Starting from January 1, 2012, a cytopathology expert team in the Zaandam laboratory began reviewing defined categories of clinical cytology specimens from the Alkmaar and Hoorn pathology laboratories, resulting in a consensus diagnosis. The team consisted of two expert cytopathologists (DSG and $\mathrm{MV})$. A second review was performed blinded to the initial diagnoses. The following types of specimens were routinely sent for intradepartmental second review: difficult or suspicious cases and cases with a discrepancy between the general pathologists' diagnoses, with the clinical presentation or with immunohistochemical stains.

The cytopathologists were either consulted before case sign-out, when the initial pathologist was unable to offer a preliminary diagnosis, or asked for a second opinion after preliminary sign-out. For the purpose of this study, the cases where the expert cytopathologists were consulted pre-sign-out were excluded from analysis. In the remaining cases, the initial diagnoses and the expert diagnoses were recorded and compared.
Assessment of concordance between initial and expert diagnoses

We thereby retrospectively assessed all clinical cytopathology cases of 2012 and 2013 that had been reviewed by the expert cytopathologists and determined concordance between initial and expert diagnoses. We applied the same definitions for minor and major discordances as described by Lueck et al. and Bomeisl et al. [32, 33]. Minor discordance was defined as a 1-step deviation on the scale of 'non-diagnostic, benign, atypical, suspicious and malignant' without an effect on treatment or prognosis. Major discordance was defined as either a deviation of $\geq 2$ steps on this scale or a discordance with effect on patient management or prognosis.

Validation of diagnoses by comparison with histological follow-up

We validated initial and expert diagnoses by comparison with same-site histological follow-up diagnoses. The process of follow-up identification is explained in the following section. The diagnosis closest to the follow-up diagnosis was deemed correct. Non-diagnostic specimens, which had insufficient diagnostic material or were non-representative, were not validated by histological follow-up.

\section{Identification of cytohistologically discordant cases}

As follow-up identification is a very time-consuming activity, a cytotechnician at Symbiant (HdL) developed the follow-up tool Follow Up application SYMbiant (FUSYM), which provides histological follow-up for cytology specimens by automating several steps in the process. FUSYM has been developed in Microsoft Visual Studio 2010 professional and was written in Microsoft Visual Basic.

The Netherlands employs a unique system whereby all reports from the Dutch pathology laboratories are stored in a central database (PALGA) via a local server. All histological examinations subsequent to the cytological examination were routinely extracted from PALGA and loaded into FUSYM. The following was coded while loading data: tissue type, organ, sampling region, sampling method and side. Furthermore, diagnoses were classified at three levels, known as diagnostic group (unknown, non-diagnostic, benign, atypia or malignant), main diagnosis (benign was subdivided into no abnormalities, benign lesion and benign neoplasm, and malignant was subdivided into suspicious and malignant neoplasm) and specific diagnosis. Subsequently, the actual follow-up examination from the same site as the cytology specimen (i.e. same organ and sampling region) was determined manually for every cytology specimen.

Finally, cytology and histology follow-up diagnoses were compared at the level of diagnostic group to determine the 
Fig. 1 The routine cytology diagnostics process at Symbiant's three pathology laboratories. $L a b$ $A$ Alkmaar Medical Centre, $L a b B$ Westfriesgasthuis Hoorn, Lab C Zaandam Medical Centre

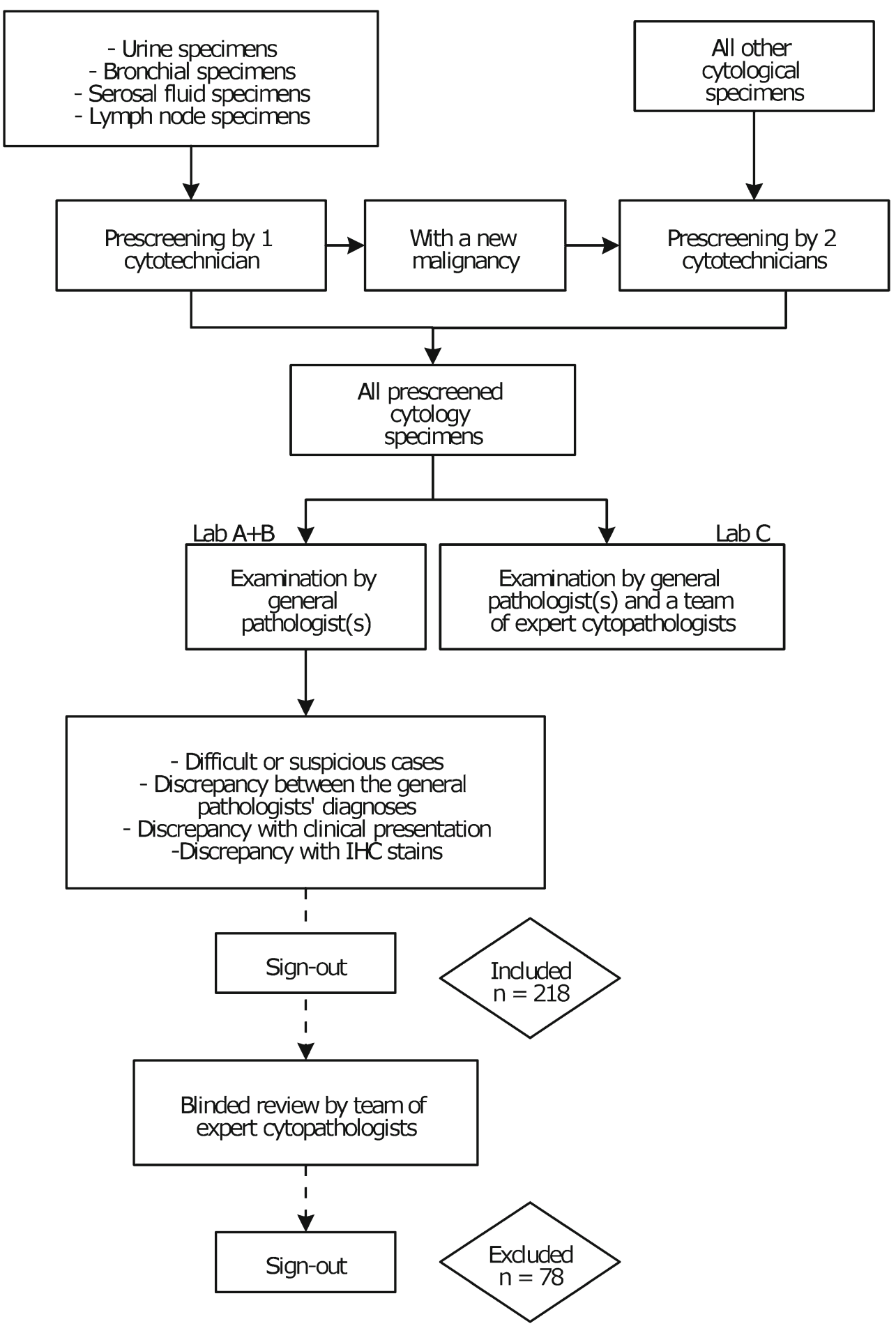

cytohistologic concordance rate and the number of 'false-negative' and 'false-positive' cytology diagnoses. Suspicious as well as malignant cytology diagnoses with a malignant histological follow-up were deemed concordant. Non-diagnostic cytology or histology specimens or specimens with a diagnosis of atypia were excluded from analysis.
Retrospective double reading of a sample of cytohistologically discordant cases initially not undergoing double reading

To assess the quality of cytodiagnostics of the cases from 2012 to 2013 that did not undergo routine double reading, 
concordance with histological follow-up was determined. Of the cytohistologically discordant cases, we randomly selected a sample of 100 specimens from the Alkmaar pathology laboratory to be retrospectively reviewed by the expert cytopathologists, blinded to the original diagnosis, and recorded whether the expert diagnosis was concordant or discordant with the initial diagnosis. A discordant diagnosis was subdivided into (1) a change from benign to malignant, or vice versa, resulting in expert cytohistologic concordance; (2) a change from benign or malignant into atypia; or (3) a change into non-diagnostic.

\section{Statistics}

Statistical analysis was performed using SPSS 20. Initial diagnoses and expert diagnoses were compared using the unweighted Cohen's kappa $(K)$ coefficient. A $K$ value of $0.00-0.20$ indicates a slight agreement, $0.21-0.40$ a fair agreement, $0.41-0.60$ a moderate agreement, $0.61-0.80$ a substantial agreement and $0.81-1$ a perfect agreement. Furthermore, the percentages of concordance and discordance with their $95 \%$ confidence intervals (CI) were calculated. $P$ values $<0.05$ were considered statistically significant.

\section{Results}

Specimens routinely undergoing double reading

During the study period, 296 clinical cytology specimens underwent routine double reading by the expert cytopathologists. We excluded 78 cases where the initial diagnoses were not recorded, because pathologists consulted the expert team before case sign-out, leaving 218 specimens. From 12 patients, multiple cytology specimens were included as separate cases (11 patients with 2 specimens and 1 patient with 3 specimens). Table 1 summarizes the tissue types and sampling methods of the 218 specimens.

Both diagnoses were concordant in 131 specimens (60.1\%; $95 \%$ CI 0.535-0.666, kappa 0.489, $P<0.0001)$. Major discordance between the initial and the expert diagnoses was seen in 28 specimens $(12.8 \%$; $95 \%$ CI $0.084-0.173)$ and minor discordance in 59 specimens $(27.1 \%$; $95 \%$ CI $0.211-0.330$ ). Table 2 summarizes the types of major and minor discordances. Of all discordant specimens, the initial diagnosis was underestimated 45 times $(51.7 \%)$ and overestimated 37 times (42.5\%). Twice, a benign diagnosis was changed into non-diagnostic, and 1 specimen was changed from non-diagnostic into malignant. Furthermore, for 1 specimen, an unspecific benign diagnosis (no malignancy) was specified into a Warthin tumour, and in another case, a diagnosis of metastatic squamous cell carcinoma was changed into metastatic adenocarcinoma.

Table 3 shows the frequencies of discordant second opinion diagnoses subdivided by the eight tissue types with $\geq 10$ specimens reviewed by the expert cytopathologists. Pleural fluid, urine and bile duct brush specimens showed the highest overall discordance rates (58.1, 50.0 and $46.2 \%$, respectively). Major discordances were most commonly observed in pleural fluid, thyroid and urine specimens with 19.4, 19.2 and $16.7 \%$, respectively. Minor discordances were most commonly observed in bile duct brush, pleural fluid and bronchial specimens with 46.2, 38.7 and $36.4 \%$, respectively. Breast cytology specimens showed the lowest discordance rate, with one minor discordant expert diagnosis $(9.1 \%)$. The total major and minor discordance percentages of this subset of specimens (tissue types with $\geq 10$ specimens) were similar to those of the whole study selection (all tissue types).

Validation by comparison with histological follow-up

Same-site histological follow-up was available for 25 of the 87 discordant specimens, but was non-diagnostic for 3 specimens. Hence, we validated the initial and expert diagnoses of 22 cytology specimens by comparison with histological follow-up. The expert diagnosis was supported by the histology diagnosis in 21/22 specimens (95.5\%; $95 \%$ CI 0.860-1.049).

Table 1 Summary of tissue types and acquisition methods of 218 clinical cytology specimens undergoing double reading by expert cytopathologists

\begin{tabular}{lll}
\hline Tissue type & Number & Percentage \\
\hline Thyroid FNA & 52 & 23.9 \\
Lymph node FNA & 40 & 18.3 \\
Pleural fluid & 31 & 14.2 \\
Salivary gland FNA & 22 & 10.1 \\
Bile duct brush & 13 & 6.0 \\
Urine & 12 & 5.5 \\
Bronchial FNA/brush/lavage & 11 & 5.0 \\
Breast FNA/nipple discharge & 11 & 5.0 \\
Ascitic fluid & 8 & 3.7 \\
Adrenal gland FNA & 6 & 2.8 \\
Liver FNA/brush & 3 & 1.4 \\
Pancreas FNA & 2 & 0.9 \\
Pericardial fluid & 2 & 0.9 \\
Cerebrospinal fluid & 1 & 0.5 \\
Peritoneal FNA & 1 & 0.5 \\
Esophageal FNA & 1 & 0.5 \\
Scrotal FNA & 1 & 0.5 \\
Retro-auricular FNA & 1 & 0.5 \\
\hline
\end{tabular}

FNA fine needle aspiration 
Table 2 Types of major discordances $(n=28)$ and minor discordances $(n=59)$ for clinical cytology specimens undergoing double reading by expert cytopathologists

\begin{tabular}{clllll}
\hline Type of major discordance & Number & Percentage & Type of minor discordance & Number & Percentage \\
\hline Underestimated & 14 & 50.0 & Underestimated & 31 & 52.6 \\
Benign $\rightarrow$ suspicious & 4 & 14.3 & Benign $\rightarrow$ atypia & 1 & 1.7 \\
Benign $\rightarrow$ malignant & 3 & 10.7 & Atypia $\rightarrow$ suspicious & 7 & 11.9 \\
Atypia $\rightarrow$ malignant & 7 & 25.0 & Suspicious $\rightarrow$ malignant & 23 & 39.0 \\
Overestimated & 13 & 46.4 & Overestimated & 24 & 40.7 \\
Malignant $\rightarrow$ atypia & 1 & 3.6 & Malignant $\rightarrow$ suspicious & 2 & 3.4 \\
Malignant $\rightarrow$ benign & 2 & 7.1 & Suspicious $\rightarrow$ atypia & 7 & 11.9 \\
Suspicious $\rightarrow$ benign & 10 & 35.7 & Atypia $\rightarrow$ benign & 15 & 25.4 \\
Other & 1 & 3.6 & Other & 4 & 6.8 \\
\hline
\end{tabular}

The case that was not supported by histology revealed a malignant mesothelioma, which was not diagnosed in the pleural fluid cytology by both the initial pathologist as well as the expert cytopathologist.

Retrospective second review of cytohistologically discordant cases

In order to get an impression of the quality of cytology diagnostics in those specimens that did not undergo double reading in routine diagnostics, we determined the rates of concordance and discordance with histological follow-up in these specimens. Same-site histological follow-up was available for 1613 cases, of which we excluded 338 cases, because either cytology, histology or both were non-diagnostic or had a diagnosis of atypia. Furthermore, we excluded 24 cases with a time period between cytological and histological examination longer than 6 months and 17 cases with only a few malignant cells on histology, leaving 1234 cases. Cytohistological concordance was found for 943 cytology specimens (76.4\%; $95 \%$ CI 0.740-0.788), and 291 cytology specimens $(23.6 \%)$ had a discordant histological follow-up.

For the random sample of 100 cytohistologically discordant cases from the Alkmaar pathology laboratory, the expert diagnosis was consistent with the initial diagnosis in $57 \%$
(95\% CI 0.471-0.669). The cytopathologists changed the diagnosis in $43 \%$ of cases: in 17 cases, the diagnosis was changed from benign to malignant (10 cases) or vice versa ( 7 cases), resulting in cytohistological concordance; a benign or malignant diagnosis was changed into atypia in 8 cases, and a diagnosis was changed into non-diagnostic 18 times.

\section{Discussion}

This study assessed the added value of our implemented intradepartmental double reading strategy of defined categories of clinical cytology specimens by a team of expert cytopathologists. We demonstrated a $60.1 \%$ concordance rate, a $12.8 \%$ major discordance rate and a $27.1 \%$ minor discordance rate between initial and expert diagnoses. The highest major discordance rates were observed in pleural fluid, thyroid and urine specimens. Validation by comparison with same-site histological follow-up confirmed that expert diagnoses were correct in 95.5\% (95\% CI 0.860-1.049). These findings emphasize the importance of double reading of selected specimens by expert cytopathologists.

Previous studies on cytopathology double reading demonstrated somewhat lower major discordance rates (7.4 to $9.3 \%$ ) [32-34], probably due to differences in specimen selection. At
Table 3 Frequencies of discordances subdivided by tissue type

Tissue types with $\geq 10$ cytology specimens reviewed by the expert cytopathologists were compared FNA fine needle aspiration

\begin{tabular}{lllll}
\hline Tissue type & $\begin{array}{l}\text { Number of } \\
\text { specimens }\end{array}$ & $\begin{array}{l}\text { Total discordant } \\
\text { expert diagnoses }\end{array}$ & $\begin{array}{l}\text { Major } \\
\text { discordance }\end{array}$ & $\begin{array}{l}\text { Minor } \\
\text { discordance }\end{array}$ \\
\hline Pleural fluid & 31 & $18(58.1 \%)$ & $6(19.4 \%)$ & $12(38.7 \%)$ \\
Urine & 12 & $6(50.0 \%)$ & $2(16.7 \%)$ & $4(33.3 \%)$ \\
Bile duct brush & 13 & $6(46.2 \%)$ & - & $6(46.2 \%)$ \\
Bronchial FNA/brush/lavage & 11 & $5(45.5 \%)$ & $1(9.1 \%)$ & $4(36.4 \%)$ \\
Thyroid FNA & 52 & $23(44.2 \%)$ & $10(19.2 \%)$ & $13(25.0 \%)$ \\
Lymph node FNA & 40 & $11(27.5 \%)$ & $6(15.0 \%)$ & $5(12.5 \%)$ \\
Salivary gland FNA & 22 & $6(27.3 \%)$ & - & $6(27.3 \%)$ \\
Breast FNA/nipple discharge & 11 & $1(9.1 \%)$ & - & $1(9.1 \%)$ \\
Total & 192 & $76(39.6 \%)$ & $25(13.0 \%)$ & $51(26.6 \%)$ \\
\hline
\end{tabular}


our institution, defined categories of clinical cytology specimens were reviewed, whereas others described second review of all referred cytopathology material before definitive treatment. Furthermore, we specifically assessed the added value of double reading by expert cytopathologists. In these studies as well, high major disagreement rates of thyroid FNA specimens were observed (16.2 to $24.3 \%$ ), and in the study of Lueck et al. [32], major discrepancies in urine specimens were the third most common (16.2\%).

The high discordance rates in urine and pleural fluid specimens might be partly explained by the lack of standard terminology and the use of inadequate terms, especially for atypical lesions [35]. Implementation of the Paris System for Urinary Cytopathology, which is currently being developed, might improve urine cytology diagnostics [36]. This explanation does, however, not hold true for thyroid cytology specimens, because of well-defined terminology in the Bethesda System for Reporting Thyroid Cytopathology (BSRTC) [37]. We therefore suppose that most discrepancies were a result of inadequate interpretation instead of inadequate terms used. The majority of thyroid cytology discrepancies were caused by initial overestimation of benign and atypical specimens.

Initial underestimation occurred in slightly more discordant cytology specimens than overestimation did (51.7 and $42.5 \%$, respectively). This difference mainly represented minor discordant specimens, of which malignancies being underestimated as suspicious were most commonly observed, indicating reluctance among general pathologists to label cases as malignant. Among the major discordant specimens, the proportions of underestimated and overestimated diagnoses by general pathologists were evenly distributed.

A limitation of this study is the relatively small availability of same-site histological follow-up (in 25/87 discordant specimens) to validate expert diagnoses, which may lead to partial verification bias. Reasons for the absence of same-site histological follow-up were assessed. They included the presence of a benign cytology or benign follow-up cytology diagnosis $(n=$ 18 ), the presence of histological follow-up obtained from another related site $(n=10)$ or radiological follow-up $(n=3)$. For 17 patients, histological follow-up would have been superfluous, because they already suffered from incurable metastatic malignancies. Furthermore, 12 patients were treated in an academic hospital or another local hospital, of which patient charts were unavailable to us, and 1 patient died very shortly after cytological examination. Finally, for 1 patient with an atypical thyroid cytology specimen, an intended hemithyroidectomy was probably cancelled for an, to us, unknown reason.

Our double reading strategy reveals major discordant diagnoses in a substantial number of cytology cases. Although standard double reading of all cytology specimens would be ideal in terms of patient safety, it would significantly increase workload and costs of pathology. Alternatively, all cytology could be signed out by expert cytopathologists, but this is in general pathology practice difficult to realize. In line with the present results, Raab et al. [38] demonstrated that focused review of diagnostically challenging areas of surgical pathology was more time- and cost-effective than $5 \%$ random review and detected a significantly higher frequency of discrepancies. In order to get an impression of the quality of cytology diagnostics in those specimens that did not undergo double reading in routine diagnostics, we determined the concordance rate with histological follow-up, which appeared to be $76.4 \%$. Retrospective double reading of a random sample of 100 cytohistologically discordant specimens changed the diagnosis in 43 cases, with urine and lymph node specimens most commonly adapted. In these cases, the sign-out pathologist probably had been sufficiently confident of the diagnosis and therefore had not consulted the expert cytopathologists. This argues for investigating which further specimen types are problematic as well and would probably also benefit from initial double reading, in order to refine the double reading strategy.

Patient safety is of utmost importance, and, in our opinion, cytopathology is a subspecialization of pathology that requires specialized cytopathologists, because the discordance rates are unacceptably high. The Dutch thyroid carcinoma guideline [39] states that 'thyroid FNAs should be assessed by a pathologist with interest and experience in thyroid cytology and histology, who can recommend management or treatment based on the cytology results. If an experienced pathologist is not available locally, the sample should be sent to a pathologist that does have expertise in this field.' Also, the Dutch bladder carcinoma guideline [40] states that 'reliability of urine cytology evaluation is dependent on the expertise of the (cyto)pathologist.' The Board of Pathology of the European Union of Medical Specialists (UEMS) published requirements for recognition of postgraduate training in pathology and stated that cytopathology is an integral part of pathology and well-trained pathologists must be able to cover basic cytological diagnosis [41]. Pathologists can obtain post-graduate 'advanced level of competence' certificates in cytopathology [41]. We agree with Anshu et al. [42] who stated that 'European and international guidelines for training and accreditation in cytopathology should be developed with some urgency'. Guidelines should include an annual minimum number of specimens that a (cyto)pathologist must view and recommendations for further education and examination.

\section{Conclusion}

Our implemented double reading strategy of defined categories of cytology specimens showed major discordance in $12.8 \%$ of specimens. The expert review was supported in $95.5 \%$ of discordant cases where histological follow-up was available. This indicates that this double reading strategy is worthwhile and contributes to better cytodiagnostics and quality of patient 
care, especially for suspicious pleural fluid, thyroid and urine specimens. Although it is currently not reimbursed and formal cost-effectiveness studies are lacking, we believe that selected second review may prevent overtreatment of a subgroup of patients in a cost-effective way and, also in the light of the upcoming claim culture in Europe, should therefore be considered for regular reimbursement. Our results emphasize that cytopathology is a subspecialization of pathology and requires specialized cytopathologists.

Acknowledgments The authors would like to thank Alice van Berne for her excellent editing work.

\section{Compliance with Ethics Guidelines}

Conflict of interest The authors declare that they have no conflict of interest.

Research involving human participants and/or animals Not applicable.

Informed consent Since we used archival pathology material which does not interfere with patient care and does not involve the physical involvement of the patient, no ethical approval is required according to Dutch legislation [the Medical Research Involving Human Subjects Act (Wet medisch-wetenschappelijk onderzoek met mensen, WMO [43])]. Use of anonymous or coded leftover material for scientific purposes is part of the standard treatment contract with patients, and therefore informed consent procedure was not required according to our institutional medical ethical review board. This has also been described by van Diest et al. [44]. We consider our study to be subjected to exemption from the federal regulation as has been suggested below: Exemption 4 includes research involving the collection or study of existing data, documents, records, pathological specimens or diagnostic specimens, if these sources are publicly available or if the information is recorded by the investigator in such a manner that subjects cannot be identified, directly or through identifiers linked to the subjects [45]. Also, this is based on the Dutch guidelines for research [46].

Open Access This article is distributed under the terms of the Creative Commons Attribution License which permits any use, distribution, and reproduction in any medium, provided the original author(s) and the source are credited.

\section{References}

1. Kohn LT, Corrigna JM, Donaldson MS (1999) To err is human; building a safer health system. Institute of Medicine, National Academy Press, Washington DC

2. Tomaszewski JE, Bear HD, Connally JA, Epstein JI, Feldman M, Foucar K, Layfield L, LiVolsi V, Sirota RL, Stoler MH, Stombler RE (2000) Consensus conference on second opinions in diagnostic anatomic pathology. Who, what, and when. Am J Clin Pathol 114:329-335

3. Swapp RE, Aubry MC, Salomao DR, Cheville JC (2013) Outside case review of surgical pathology for referred patients: the impact on patient care. Arch Pathol Lab Med 137:233-240

4. Gaudi S, Zarandona JM, Raab SS, English JC 3rd, Jukic DM (2013) Discrepancies in dermatopathology diagnoses: the role of second review policies and dermatopathology fellowship training. J Am Acad Dermatol 68:119-128
5. Matasar MJ, Shi W, Silberstien J, Lin O, Busam KJ, Teruya-Feldstein J, Filippa DA, Zelenetz AD, Noy A (2012) Expert second-opinion pathology review of lymphoma in the era of the World Health Organization classification. Ann Oncol 23:159-166

6. LaCasce AS, Kho ME, Friedberg JW, Niland JC, Abel GA, Rodriguez MA, Czuczman MS, Millenson MM, Zelenetz AD, Weeks JC (2008) Comparison of referring and final pathology for patients with non-Hodgkin's lymphoma in the National Comprehensive Cancer Network. J Clin Oncol 26:5107-5112

7. Brimo F, Schultz L, Epstein JI (2010) The value of mandatory second opinion pathology review of prostate needle biopsy interpretation before radical prostatectomy. J Urol 184:126-130

8. Nguyen PL, Schultz D, Renshaw AA, Vollmer RT, Welch WR, Cote K, D'Amico AV (2004) The impact of pathology review on treatment recommendations for patients with adenocarcinoma of the prostate. Urol Oncol 22:295-299

9. Wurzer JC, Al Saleem TI, Hanlon AL, Freedman GM, Patchefsky A, Hanks GE (1998) Histopathologic review of prostate biopsies from patients referred to a comprehensive cancer center: correlation of pathologic findings, analysis of cost, and impact on treatment. Cancer 83:753-759

10. Lee MC, Levin HS, Jones JS (2010) The role of pathology review of transurethral bladder tumor resection specimens in the modern era. $\mathrm{J}$ Urol 183:921-927

11. Jones K, Jordan RC (2010) Patterns of second-opinion diagnosis in oral and maxillofacial pathology. Oral Surg Oral Med Oral Pathol Oral Radiol Endod 109:865-869

12. Zembowicz A, Ahmad A, Lyle SR (2011) A comprehensive analysis of a web-based dermatopathology second opinion consultation practice. Arch Pathol Lab Med 135:379-383

13. Lurkin A, Ducimetiere F, Vince DR, Decouvelaere AV, Cellier D, Gilly FN, Salameire D, Biron P, de Laroche G, Blay JY, RayCoquard I (2010) Epidemiological evaluation of concordance between initial diagnosis and central pathology review in a comprehensive and prospective series of sarcoma patients in the Rhone-Alpes region. BMC Cancer 10:150

14. Arbiser ZK, Folpe AL, Weiss SW (2001) Consultative (expert) second opinions in soft tissue pathology. Analysis of problem-prone diagnostic situations. Am J Clin Pathol 116:473-476

15. Hahm GK, Niemann TH, Lucas JG, Frankel WL (2001) The value of second opinion in gastrointestinal and liver pathology. Arch Pathol Lab Med 125:736-739

16. Chafe S, Honore L, Pearcey R, Capstick V (2000) An analysis of the impact of pathology review in gynecologic cancer. Int J Radiat Oncol Biol Phys 48:1433-1438

17. Khalifa MA, Dodge J, Covens A, Osborne R, Ackerman I (2003) Slide review in gynecologic oncology ensures completeness of reporting and diagnostic accuracy. Gynecol Oncol 90:425-430

18. Bruner JM, Inouye L, Fuller GN, Langford LA (1997) Diagnostic discrepancies and their clinical impact in a neuropathology referral practice. Cancer 79:796-803

19. Wayment RO, Bourne A, Kay P, Tarter TH (2011) Second opinion pathology in tertiary care of patients with urologic malignancies. Urol Oncol 29:194-198

20. Santoso JT, Coleman RL, Voet RL, Bernstein SG, Lifshitz S, Miller D (1998) Pathology slide review in gynecologic oncology. Obstet Gynecol 91:730-734

21. Scott CB, Nelson JS, Farnan NC, Curran WJ Jr, Murray KJ, Fischbach AJ, Gaspar LE, Nelson DF (1995) Central pathology review in clinical trials for patients with malignant glioma. A report of Radiation Therapy Oncology Group 83-02. Cancer 76:307-313

22. Aldape K, Simmons ML, Davis RL, Miike R, Wiencke J, Barger G, Lee M, Chen P, Wrensch M (2000) Discrepancies in diagnoses of neuroepithelial neoplasms: the San Francisco Bay Area Adult Glioma Study. Cancer 88:2342-2349 
23. Romanoff AM, Cohen A, Schmidt H, Weltz CR, Jaffer SM, Nagi CS, Bleiweiss IJ, Port ER (2014) Breast pathology review: does it make a difference? Ann Surg Oncol 21:3504-3508

24. Marco V, Muntal T, García-Hernandez F, Cortes J, Gonzalez B, Rubio IT (2014) Changes in breast cancer reports after pathology second opinion. Breast J 20:295-301

25. Baloch ZW, Hendreen S, Gupta PK, LiVolsi VA, Mandel SJ, Weber R, Fraker D (2001) Interinstitutional review of thyroid fine-needle aspirations: impact on clinical management of thyroid nodules. Diagn Cytopathol 25:231-234

26. Tan YY, Kebebew E, Reiff E, Caron NR, Ogilvie JB, Duh QY, Clark OH, Ljung BM, Miller T (2007) Does routine consultation of thyroid fine-needle aspiration cytology change surgical management? J Am Coll Surg 205:8-12

27. Davidov T, Trooskin SZ, Shanker BA, Yip D, Eng O, Crystal J, Hu J, Chernyavsky VS, Deen MF, May M, Artymyshyn RL (2010) Routine second-opinion cytopathology review of thyroid fine needle aspiration biopsies reduces diagnostic thyroidectomy. Surgery 148: 1294-1299

28. Park JH, Kim HK, Kang SW, Jeong JJ, Nam KH, Chung WY, Park CS (2012) Second opinion in thyroid fine-needle aspiration biopsy by the Bethesda system. Endocr J 59:205-212

29. Bajaj J, Morgenstern N, Sugrue C, Wasserman J, Wasserman P (2012) Clinical impact of second opinion in thyroid fine needle aspiration cytology (FNAC): a study of 922 interinstitutional consultations. Diagn Cytopathol 40:422-429

30. Olson MT, Boonyaarunnate T, Aragon Han P, Umbricht CB, Ali SZ, Zeiger MA (2013) A tertiary center's experience with second review of 3885 thyroid cytopathology specimens. J Clin Endocrinol Metab 98:1450-1457

31. Kronz JD, Westra WH (2005) The role of second opinion pathology in the management of lesions of the head and neck. Curr Opin Otolaryngol Head Neck Surg 13:81-84

32. Lueck N, Jensen C, Cohen MB, Weydert JA (2009) Mandatory second opinion in cytopathology. Cancer 117:82-91

33. Bomeisl PE Jr, Alam S, Wakely PE Jr (2009) Interinstitutional consultation in fine-needle aspiration cytopathology: a study of 742 cases. Cancer 117:237-246
34. Layfield LJ, Jones C, Rowe L, Gopez EV (2002) Institutional review of outside cytology materials: a retrospective analysis of two institutions' experiences. Diagn Cytopathol 26:45-48

35. Owens CL, Vandenbussche CJ, Burroughs FH, Rosenthal DL (2013) A review of reporting systems and terminology for urine cytology. Cancer Cytopathol 121:9-14

36. The Paris reporting system for urinary cytopathology. Available: https://paris.soc.wisc.edu/index.htm. Accessed 28 Jan 2015

37. Cibas ES, Ali SZ (2009) The Bethesda system for reporting thyroid cytopathology. Thyroid 19:1159-1165

38. Raab SS, Grzybicki DM, Mahood LK, Parwani AV, Kuan SF, Rao UN (2008) Effectiveness of random and focused review in detecting surgical pathology error. Am J Clin Pathol 130:905-912

39. Dutch thyroid carcinoma guideline. Available: http://www.oncoline. $\mathrm{nl} /$ index.php?pagina=/richtlijn/item/pagina.php\&richtlijn_id=554. Accessed 28 Jan 2015

40. Dutch bladder carcinoma guideline. Available: http://www.oncoline. nl/bladdercarcinoma. Accessed 28 Jan 2015

41. Totsch M, Cuvelier C, Vass L, Fassina A (2012) The UEMS section/ board of pathology, chapter 6: requirement for recognition of postgraduate training in pathology: a presentation of the paris document. Cytopathology 23:295-299

42. Anshu, Herbert A, Cochand-Priollet B, Cross P, Desai M et al (2010) Survey of medical training in cytopathology carried out by the journal Cytopathology. Cytopathology 21:147-156

43. Central Committee on Research involving Human Subjects (Centrale Commissie Mensgebonden Onderzoek) (text in Dutch). Available: http://www.ccmo.nl/nl/niet-wmo-onderzoek. Accessed 28 Jan 2015

44. van Diest PJ (2002) No consent should be needed for using leftover body material for scientific purposes. For. BMJ 325:648-651

45. Federal policy for the protection of human subjects. Available: http:/ www.fda.gov/ScienceResearch/SpecialTopics/ RunningClinicalTrials/ucm118862.htm. Accessed 28 Jan 2015

46. Gedragscode verantwoord omgaan met lichaamsmateriaal ten behoeve van wetenschappelijk onderzoek (text in Dutch). Available: http://www.kncv.nl/Uploads/2011/9/pdf-Code-GoedGebruik-met-logo-Federa-Coreon.pdf. Accessed 28 Jan 2015 